\title{
CÉSAR VALLEJO: MADRID, 1978
}

\author{
Carlos Eduardo Zavaleta
}

Sabemos que, para 1978, hacía cuarenta años que César Vallejo había muerto. Y sabemos también que, por entonces, en España, los libros del poeta peruano (en especial, los de la editorial catalana Laia, la cual se hallaba a medio camino de lanzar las Obras Completas) circulaban, sí, pero con algunas limitaciones, pues los títulos de temas políticos seguían bajo la mirada selectiva del personal uniformado.

Por supuesto que el caudillo Francisco Franco había muerto a su vez en 1975, y que desde esta importante fecha se suponía que las restricciones político-culturales iban a aflojarse lentamente, y en efecto sucedió así, pues lentas son las medidas que corrigen circunstancias históricas.

El copyright o los derechos de autor habían sido fijados por Georgette de Vallejo en Lima, en 1975, fecha que coincide con la muerte de Franco, y sin duda también con el afán de aprovechar la nueva situación española y difundir del todo a un poeta muy vinculado con el país ibérico, pero donde ciertos títulos como España, aparta de mi este cáliz, sólo se publicaron en setiembre de 1977. Este tomo lleva el VIII número de la colección, y además, una banda verde de propaganda, cuyo texto reza: «El presentimiento de dos muertes paralelas: la de un hombre y la 
de un pueblo. ESPAÑA, APARTA DE MÍ ESTE CÁLIZ. (En el 40 aniversario de la muerte de Vallejo, primera edición en España) $)^{1}$

Como se ve, la edición anticipa la notoriedad del año 1978, en que se cumplirían cuatro décadas de la muerte de Vallejo.

De algún modo, se esperaba, pues, un homenaje. Pero no vino del lado español, sino del nuestro. Un peruano que viviera en Madrid por aquel tiempo tenía que esperar un acto reivindicatorio y de magnitud nacional. Entonces, como una iniciativa natural, la Embajada del Perú, de la cual yo formaba parte, lanzó por escrito una iniciativa dirigida en especial a los medios de comunicación y a las instituciones culturales, invitándoles a sumarse al homenaje y a la mayor difusión de la obra del vate. El primer llamado fue una circular del 15 de marzo, y el segundo, un formal Boletín de Prensa, del 11 de abril de 1978 .

La cosecha fue variada. El punto fuerte fue la organización, por primera vez en Madrid, de una nutrida Exposición Bibliográfica "Recuerdo de Vallejo", en el Instituto de Cooperación Iberoamericana, con títulos obtenidos de las principales bibliotecas de la ciudad, de la Embajada peruana, de amigos latinoamericanos, y de algunos préstamos directos, como el de Gerardo Diego, amigo de Vallejo, y de José Bergamín (el también amigo y prologuista de la segunda edición de Trilce), quien publicó un artículo alusivo, así como del notable poeta español Luis Rosales, que durante décadas, aun bajo la dictadura de Franco, exhibía en su despacho del antiguo Instituto de Cultura Hispánica un gran retrato de Vallejo, tomado por Juan Domingo Córdoba, y cuyos poemas se sabía de memoria, al igual

1 César Vallejo, Obras completas, vol. VIII. Poemas humanos, España, aparta de mi este cáliz (Barcelona: Laia, setiembre 1977, Copyright by Georgette de Vallejo, Lima 1975). No me refiero aqui, por supuesto, a otras ediciones españolas, legales o no, desde 1938 en adelante. 
que el asimismo poeta Félix Grande, devoto vallejiano y aplaudido responsable de los dos vastos tomos de Cuadernos Hispanoamericanos, que constituyen otro homenaje, en 1988, diez años después del citado aquí. Un grupo de estas personalidades aparece en una fotografía, en torno al Embajador Carlos Vásquez Ayllón y al Ministro de Educación peruano, Otto Elespuru, quien viajó a Madrid e inauguró la muestra.

Otros actos principales fueron un recital poético en el auditorio del diario "El Pueblo", con la intervención de los poetas Elvira Roca Rey y Walter Curonisy, una ceremonia en el local Amigos de la UNESCO, donde habló, entre varios, el escritor Hugo Neyra, nuevas conferencias sucesivas en Cádiz, Granada y Palma de Mallorca, organizadas por Carlos Meneses y por mí, y sendos homenajes en el diario $A B C$ (30 de abril), en la revista Estafeta Literaria (15 de abril), en el suplemento cyktyrka de Informaciones (13 de abril) y hasta en el oficialista El Alcázar. Las estaciones de radio fueron muy cumplidas en trasmitir noticias alusivas a los actos.

Por supuesto que superamos algunos escollos, por ejemplo, la extraña interferencia del Ministerio de Gobernación, que en vano quiso sustituir a la Cancillería española en coordinar detalles sobre el recital poético, pidiendo de antemano los textos que iban a leerse. Por el mismo canal diplomático previo, la Embajada esclareció posiciones y adujo que el gobierno peruano jamás había exigido condiciones semejantes a la Embajada española en Lima, y que por tanto, por reciprocidad, no cabía pedido alguno de textos. Cesó la intervención, pero en el recital vimos a numerosos y silenciosos guardias uniformados.

Pocos años atrás, bajo el franquismo, cuando admiradores españoles y latinoamericanos de Pablo Neruda habían pretendido conmemorar un aniversario de su muerte, fueron duramente dispersados por la policía, la cual explicó que en el acto sólo estaba permitido para cien personas, y como había un número mayor, pues se le suspendía y punto. Esa vez, por excepción, saliendo de su antiguo silencio, el $A B C$ sí rindió homenaje a Neruda. 
Entre los artículos conmemorativos, debo destacar los del vespertino Informaciones suscritos por Gerardo Diego, Félix Grande, Carlos Meneses, Marco Ricardo Barnatán y Carlos Zavaleta. $^{2}$

En el $A B C$ publicamos artículos J.L Castillo-Puche, Lorenzo López Sancho y el que esto escribe. Inclusive solicité un artículo al joven escritor peruano que visitaba por entonces Madrid, Alonso Cueto, cuyo texto se publicó en el Diario 16 de la ciudad. ${ }^{3}$

En fin, en la revista Estafeta Literaria aparecieron dos notorios artículos, uno de Manuel Alcántara y otro firmado por mí. ${ }^{4}$ Varios de estos textos aparecieron ilustrados por fotografías y dibujos.

Del resto de publicaciones, sobre todo el El Alcázar, diario falangista, opuesto a las ideas de Vallejo, pero que, sin embargo, le rindió asimismo homenaje, no guardo copia, debido a un lamentable error. Al volver de Madrid a Lima, en los años 80, traje un archivo de tales artículos y actuaciones, el cual era por supuesto copia de algunos oficios y anexos que a su hora enviamos desde la Embajada peruana a nuestra Cancillería de Torre Tagle. Como ya ese archivo oficial me era ajeno, conservé

2 Gerardo Diego, "Recuerdo de César Vallejo»; Félix Grande, "Semejante Mendigo"; Marcos Ricardo Barnatán, "Retrato esplendor»; Carlos Meneses, "Presencia de César Vallejo en España»; y Carlos Zavaleta, «Prosa y Poesía de César Vallejo, Informaciones (Madrid, 15 de abril 1978).

3 J.L. Castillo Puche, "César Vallejo, arquetipo cristiano", $A B C$ (Madrid, 23 de abril, 1998); Lorenzo López Sancho, "César Vallejo", $A B C$ (Madrid, 14 abril 1978); Carlos Zavaleta, «La merecida fama de César Vallejo", $A B C$ (Madrid, 30 de abril 1978); y Alonso Cueto, "El desgarramiento testimonial de César Vallejo", Diario 16 (Madrid, 17 de abril 1978).

Manuel Alcántara, "Con un palo y también con una soga"; y Carlos Zavaleta, *El angustiado y tierno César Vallejo-. Estafeta Literaria (Madrid, $\mathrm{N}^{\circ}$ 634, 15 abril 1978), 
unas fotocopias para darlas a conocer en Lima. Volvía yo al cabo de dieciséis años. Mis colegas de la facultad de letras de San Marcos me dijeron que el único y mejor Instituto de Estudios Vallejianos del país funcionaba en Trujillo. Les presté oídos. En la primera ocasión, cuando me invitaron a un congreso literario en Trujillo, allá me llevé el archivo (dejando, menos mal, unas fotocopias en Lima), y en una ceremonia pública, lo entregué al entonces Director del Instituto, Germán Patrón Candela, quien prometió divulgarlo. No pude dudar de un buen hombre. Así pasó el tiempo y después viajé largamente a Londres. Hace poco me enteré de que Germán Patrón Candela había muerto. Las desconexiones en el Perú son tan increíbles como en un cuento. En fin, tomé aliento y viajé a Trujillo hace dos meses. Menos mal que, como dije, tenía algunas fotocopias en Lima. Si no, no habría podido escribir este artículo. 